\title{
A NECESSÁRIA PRESENÇA DO ESTADO NA ECONOMIA FRENTE AO APROFUNDAMENTO DA GLOBALIZAÇÃO
}

\author{
Juliani Cristina Lima Grochoski ${ }^{1}$ \\ Miguel Etinger de Araujo Júnior ${ }^{2}$
}

\section{RESUMO}

$\mathrm{O}$ artigo pretende discutir a posição do Estado frente ao fortalecimento de grupos empresariais, com grande potencial econômico e o enfraquecimento da soberania econômica e legislativa dos países. Ao comparar o capital público dos países, com o capital particular das empresas, fica evidente o poder que as mesmas detêm. Por conta da competitividade e do poder acumulado pelo capital privado, a proteções aos direitos humanos têm sido minoradas, as leis trabalhistas e ambientais flexibilizadas. O que se pretende por meio do presente, é discutir como o Estado deve intervir frente as relações contemporâneas.

Palavras-chave: Intervenção do Estado; Globalização Economia; Direitos Sociais; Soberania

\section{THE NECESSARY PRESENCE OF THE STATE IN THE ECONOMY IN THE DIFFERENCE OF GLOBALIZATION}

\begin{abstract}
The article intends to discuss the State's position regarding the strengthening of business groups with great economic potential and the weakening of the economic and legislative sovereignty of the countries. When comparing the public capital of the countries with the private capital of the companies, the power they hold is evident. Because of the competitiveness and power accumulated by private capital, human rights protections have been reduced, labor and environmental laws have been relaxed. What is intended by the present is to discuss how the state should intervene in relation to contemporary relations.
\end{abstract}

Keywords: State intervention; Globalization Economy; Social rights; Sovereignty

\section{INTRODUÇÃO}

O presente trabalho, por meio do estudo bibliográfico e da lógica dedutiva, pretende discutir a posição do Estado no contexto de aprofundamento da globalização, especialmente

\footnotetext{
O presente trabalho foi realizado com apoio da Coordenação de Aperfeiçoamento de Pessoal Nível Superior -Brasil (CAPES)

${ }^{1}$ Graduada em direito na Universidade Estadual de Maringá, Mestranda em Direito Negocial da Universidade Estadual de Londrina. Advogada. Vinculada ao projeto "Direito à Cidade e Justiça Ambiental”. Bolsista CAPES, Advogada. Email: juliani_sji@hotmail.com

${ }^{2}$ Professor de Direito Ambiental e Urbanístico nos programas de Graduação e Pós Graduação Strictu Sensu em Direito da Universidade Estadual de Londrina. Doutor em Direito da Cidade pela UERJ. Coordenador da Região Sul do Instituto Brasileiro de Direito Urbanístico. Coordenador do projeto de pesquisa "Direito à Cidade e Justiça Ambiental” Email: miguel@uel.br
} 
por conta da vulnerabilidade da soberania econômica diante do capital privado. É notável na atualidade uma grande tendência à flexibilização legislativa, que possui relação com o aumento de poder do capital por parte das empresas de natureza privada. Esse aumento tem abalado a relação entre o público e o privado, visto que, este último tem influenciado nas decisões de natureza pública.

Em um primeiro momento, o texto aponta um comparativo entre o Produto Interno Bruto dos Países e o capital das maiores empresas mundiais, demonstrado como a soberania econômica nacional passa por um processo de desconstrução diante da força do capital privado. Por conta dessa disparidade, muitos autores têm apontado uma união dos países, como alternativa para diminuir suas vulnerabilidades.

Esta pode ser uma alternativa viável, contudo, não é a única alternativa. O texto vai discutir os pontos negativos de uma possível junção de forças, que tem como objetivo uma nova ordem dos países. A partir de uma perspectiva histórica, pode-se perceber que a concentração de poder pode ser algo perigoso. Ademais, é possível que a homogeneidade da cultura e da legislação facilite a dominação por parte do capital privado.

Como alternativa a esse posicionamento, apresenta como opção uma reforma na gestão e no modo de atuação do Estado, que possa recuperar a credibilidade e a funcionalidade do mesmo. Conferindo maior eficiência na garantia dos direitos sociais, mas que também facilite o fluxo da economia, por meio de uma intervenção normativa.

Na segunda parte, o artigo vai discutir como essa intervenção poderia se dar. Por meio da perspectiva notada por Habermas, o trabalho pretende demonstrar que as marcas históricas apontam para uma posição de equilíbrio entre crescimento econômico e garantia dos direitos sociais.

Posteriormente, o trabalho discute a perspectiva inusitada proposta por Hernando de Soto, que olha o capital de forma inversa. Ou seja, a partir da ótica dos pobres, mostrando a capacidade de acumulação de capital gerado por essa população, esse montante, por não ser organizado e regularizado, não consegue reverter em favor dessa população.

Por esse motivo, o artigo discutirá formas de fazer com que esse capital acumulado pelos pobres possa circular e promover socialmente os países em desenvolvimento. Como possível solução, sugere uma intervenção normativa a partir das ideias de Norberto Bobbio, que propõe normas facilitadoras, as mesmas podem contribuir para incentivar a regularização do capital desorganizado, permitindo assim que o mesmo reverta em favor da economia dos países em desenvolvimento. Por fim, fortalecidos economicamente, os Estados terão maior capacidade 
de impor limites à intervenção do capital privado.

\section{1- DESCONSTRUÇÃO DA IDEIA DE SOBERANIA ECONÔMICA NACIONAL}

Grandes foram as batalhas que definiram os limites dos Estados Nacionais que conhecemos hoje, a luta por soberania exigiu esforço diplomático e sacrificou muitas vidas. Atualmente, a maioria quase absoluta dos Estados nacionais se consolidaram, hoje o mundo enfrenta novos desafios, dentre eles a globalização e a articulação econômica.

No cenário internacional, pode-se notar o aprofundamento proposto por David Ricardo no Século XIX, em que as barreiras fiscais já não dão conta de barrar a competitividade de produção de países como a China. Assim, a vantagem comparativa passa a consolidar a interdependência das nações. Por outro lado, a dependência dos grandes conglomerados em relação às barreiras estatais diminuíram, principalmente por conta do poder econômico das grandes empresas. Pode-se dizer então, que a contemporaneidade colocou o Estado em crise. (RICARDO, 2018).

Floriano Peixoto de Azevedo Marques Neto afirma que a crise se dá especialmente relacionada a dois aspectos: o externo e o interno. Quanto aos processos externos, os quais se dão no plano internacional, pode-se citar: o fenômeno da globalização, o desenvolvimento do capitalismo (como a internacionalização da economia), o acelerado desenvolvimento tecnológico, a interligação e interdependência dos mercados. Já os movimentos internos, remetem ao processo de desagregação social, pelo qual, se pode notar a sociedade dividida em distintos núcleos de interesses, em torno dos quais, são criadas estruturas sociais, representativas e descentralizadas. (MARQUES NETO, 2002)

Ou seja, cada dia mais o poder do Estado está se "fragmentando" e isso se dá por movimentos externos e internos. Como foi dito, grande parte desse processo se deve ao poder econômico das empresas. Em 2018, a revista Forbes lançou uma lista com as maiores empresas do mundo, essa lista permite que se compreenda o quanto do poder econômico está sobre o domínio de empresas.

Por esse motivo, o grande desafio do Estado atual, provavelmente, é lidar com empresas que possuem capital superior ao capital do próprio Estado:

A 16 $6^{\mathrm{a}}$ lista anual Global 2000 inclui empresas de capital aberto de 60 países.

Coletivamente, as companhias nesta lista representam US\$ 39,1 trilhões em 
vendas, US\$ 3,2 trilhões em lucro, US\$ 189 trilhões em ativos e US\$ 56,8 trilhões em valor de mercado. O ranking é baseado em uma pontuação composta de médias ponderadas de receita, lucros, ativos e valor de mercado. (FORBES, 2018)

Por outro lado, segundo o Instituto de Pesquisa de Relações Internacionais (IRPI), que cita dados retirados do World Economic Outloook Database, relatório elaborado pelo FMI, atualização de abril de 2017, expõe o Produto Interno Bruto (PIB), em bilhões de dólares, em 2016. O quadro abaixo mostra os 15 países com maior Produto Interno Bruto do mundo. (IPRI, 2017).

Quadro 1 - Países com maior Produto Interno Bruto

\begin{tabular}{|c|c|c|}
\hline$\#$ & País & US\$̦ bilhões \\
\hline 19 & Estados Unidos & $18.569,10$ \\
\hline 29 & China & $11.218,28$ \\
\hline $3 \circ$ & Japão & $4.938,64$ \\
\hline 49 & Alemanha* & $3.466,64$ \\
\hline 59 & Reino Unido & $2.629,19$ \\
\hline 69 & França & $2.463,22$ \\
\hline 70 & Índia & $2.256,40$ \\
\hline 89 & Itália & $1.850,74$ \\
\hline $9 \circ$ & Brasil & $1.798,62$ \\
\hline 109 & Canadá & $1.529,22$ \\
\hline 119 & Coreia do Sul & $1.411,25$ \\
\hline $12 \circ$ & Rússia & $1.280,73$ \\
\hline 13 & Austrália & $1.258,98$ \\
\hline 149 & Espanha & $1.232,60$ \\
\hline $15 \circ$ & México & $1.046,00$ \\
\hline
\end{tabular}

Fonte: Instituto de Pesquisa de Relações Internacionais.

O comparativo dos dois dados apresentados, mostra que um número reduzido de empresas (2000 empresas) que possuem US\$ 189 trilhões em ativos, ou seja, detém um capital superior a países desenvolvidos quando analisados isoladamente. Isso pode gerar uma vulnerabilidade dos Estados frente as empresas.

No mesmo sentido aponta a "Global Justicedo Now", uma organização de cunho democrático voltado à justiça social: 
As maiores corporações continuam a acumular receitas muito acima da maioria dos governos, segundo dados compilados pela Global Justice Now. Comparando as receitas de 2017, 69 das 100 principais entidadeseconômicas são corporações e não governos. As dez maiores corporações - uma lista que inclui Walmart, Toyota e Shell, além de várias corporações chinesas - arrecadaram mais de US \$ 3 trilhões no ano passado. Quando se trata das 200 maiores entidades, a diferença entre corporações e governos se torna ainda mais pronunciada: 157 são corporações. O Walmart, a Apple e a Shell acumularam mais riqueza do que países razoavelmente ricos como Rússia, Bélgica e Suécia. $^{3}$ (GLOBAL JUSTICEDO NOW, 2018, tradução nossa).

Tendo em vista o grande potencial econômico das empresas, é plenamente possível que os interesses dessas empresas influenciem as decisões dos Estados. Importa salientar que devido ao alto nível de competitividade, essas empresas já não se restringem aos seus países de origem, o que acaba forçando muitos países, especialmente os mais pobres, a cederem às suas necessidades.

Ou seja, a globalização e a ascensão das empresas contribuem para o distanciamento entre público/privado, uma vez que as exigências econômicas externas, demandadas pelos mercados financeiros e grupos econômicos (interesses privados), impõem barreiras à atuação estatal (interesses públicos). Quando um país busca uma posição que contrarie estes interesses, os investimentos externos naquele setor cessam, as empresas retiram seu capital, levando consequências sociais e econômicas, gravosas ao Estado que estavam instaladas. Ou seja, os países ficam em uma situação fragilizada em relação a chantagem do capital particular. (MARQUES NETO, 2002).

Pode-se notar que o poder de decisão não é exercido de forma absoluta pelo Estado, uma vez que, como já mencionado acima, o mercado participa de forma significativa neste processo decisório. Assim, é imprescindível pensar em mecanismos que resguardem limites à atuação do capital privado. Uma das opções seria recorrer aos organismos internacionais, que possuem estrutura própria capaz de coordenar a economia e harmonizar as diferentes

\footnotetext{
${ }^{3}$ Para dirimir qualquer erro de tradução apresenta o texto original: Top corporations continue to accrue revenues far in excess of most governments, figures compiled by Global Justice Now show. Comparing 2017 revenues, 69 of the top 100 economic entities are corporations rather than governments. The top 10 corporations - a list which includes Walmart, Toyota and Shell as well as several Chinese corporations - raked in over $\$ 3$ trillion last year. When it comes to the top 200 entities, the gap between corporations and governments gets even more pronounced: 157 are corporations. Walmart, Apple and Shell all accrued more wealth than even fairly rich countries like Russia, Belgium, Sweden.
} 
legislações, o que auxiliaria na resolução dos conflitos comerciais, garantindo o funcionamento adequado de uma economia globalizada. (BANNWART JÚNIOR, 2012)

Outra corrente, mais radical, vai além da ideia de delegar a organismos supranacionais a autoridade para mediar acordos, propondo uma governança transnacional. Dentre os autores adeptos dessa corrente estão Zenildo Bodnar e Paulo Márcio Cruz, que baseados em Ulrich Back, propõem que seja instituída uma governança transnacional, que exceda os limites geográficos instituídos. Essa governança serviria para frear os objetivos capitalistas no que toca às questões ambientais, impondo limites universais, visando à união para conservar o ambiente, tendo em vista que todos dependemos dele. (BODNAR, Zenildo, CRUZ, Paulo Márcio, 2016)

Como se pode observar pelo trecho abaixo:

Na perspectiva do cosmopolitismo, o futuro exige a consolidação de novas formas
de governança, estruturadas como uma grande teia de proteção do planeta, regidas
por princípios ecológico-sociais e que assegurem alternativas e oportunidades
democráticas mais inclusivas, participativas e emancipatórias e tenham como
preocupação garantir um mundo melhor para as futuras gerações. Somente com
novas estratégias globais de governança, baseadas na cooperação e na
solidariedade ancoradas epistemologicamente na interdisciplinaridade é que será
possível assegurar um futuro com sustentabilidade e mais justiça. Assim, conclui-
se que é necessário não só desembalar o cosmopolitismo para as Ciências Sociais,
como também para os temas essenciais da governança transnacional ambiental. (BODNAR, Zenildo, CRUZ, Paulo Márcio, 2016. p.255)

A governança transnacional teria por principal objetivo, a união dos países para proteger o meio ambiente das ingerências provocadas pelas empresas, que ocorrem principalmente por conta da flexibilização legislativa causada pela pressão do capital privado. No mesmo sentido, Habermas entende que a união dos países em blocos, como por exemplo, o a União Européia, NAFTA ou a APEC, poderia ser uma opção para estabilizar a economia dos países envolvidos, fazendo com que os blocos ficassem mais estáveis. Isso faria com que os mesmos se fortalecessem para fazer frente aos interesses do capital das grandes empresas. "Pois, com tais regimes continentais surgem não apenas questões monetárias unificadas, que diminuem os riscos das oscilações da cotação, mas também unidades políticas maiores com competências divididas de modo hierárquico" (HABERMAS, 2001, p.70).

Ou seja, é possível observar uma tendência de concentração de poder, a ideia de nação e de soberania nacional, em vários aspectos está abalada. Talvez o aspecto econômico seja o 
mais evidente, principalmente por influenciar em questões importantes e muito evidentes, como por exemplo, a questão da redução dos direitos trabalhistas e a flexibilização dos direitos ambientais. Por esse motivo, é notável uma tendência por parte de alguns autores, de apontar a união entre os países com possível solução para diminuir a vulnerabilidade do público em relação ao privado. ${ }^{4}$

Contudo, é importante questionar os possíveis pontos negativos dessa tendência. Importa por exemplo, relembrar que centros de concentração de poder Estatal, ao longo da história, foram marcados por certo grau de totalitarismos, são exemplo desse totalitarismo tanto os objetivos do Estado Nazista, quanto a União Soviética, há também outros exemplos, mas estes dois são suficientes para demonstrar que a concentração de poder é algo no mínimo perigoso.

Outra questão que deve ser levada em conta, é que no caso de uma união das nações, os países com mais poder econômico provavelmente seriam privilegiados no que toca ao poder de decisão. Da mesma forma, as dificuldades impostas pela variedade de leis dos diferentes países, seriam simplificadas, o que por um lado poderia uniformizar os padrões mínimos de conduta, e por outro, facilitaria a rápida alteração do padrão legal devido à homogeneização legislativa. Essa tendência, pode acabar refletido negativamente frente a grande onda de flexibilização legal, ou seja, é possível que a uniformização da legislação acabe nivelando por baixo a tutela dos direitos sociais.

Assim, apesar da tendência de se apontar para uma União dos Estados nacionais e da flexibilização da ideia de nação, é recomendável que sejam pensadas outras formas de se resolver a questão. Um Estado que seja equilibrado no que toca aos direitos sociais e à economia, pode ser uma alternativa para a sobrevivência dos Estados nacionais, preservando parte de sua soberania. Nesse ponto, é essencial refletir como este Estado deve se comportar em relação à intervenção no domínio econômico, e ao modelo econômico que deve ser adotado para que haja uma abertura moderada de suas fronteiras.

Um Estado que seja liberal ao extremo pode perder sua função, ou manter uma função meramente ilustrativa no cenário atual, visto que, o peso das decisões recai sobre os detentores

\footnotetext{
${ }^{4}$ Paulo Márcio Cruz e Zenildo Bodnar no texto "Cosmopolitismo e Governança Transnacional Ambiental: Uma Agenda Para o Desenvolvimento Sustentável", tratam da necessidade de uma união entre os Estados para enfrentamento das especialmente das questões ambientais. Jürgen Habermas em seu texto A constelação pósnacional: ensaios políticos, sugere a união blocos nacionais. Ambos têm tendência a entender a junção de países como uma possível solução para fortalecer o poder do Estado.
} 
do maior capital, que atualmente são as empresas.

Assim, diante da fragilidade provocada pelo aprofundamento das relações capitalistas, há a necessidade de um Estado que atenda aos interesses do cidadão que não faz parte da elite econômica, o que demonstra a importância do Estado Social.

Nesse sentido Piketty afirma que:

A redistribuição moderna e, em especial, o Estado social estabelecido nos países ricos ao longo do século $\mathrm{XX}$ foram construídos em torno de um conjunto de direitos sociais fundamentais: o direito à educação, à saúde e à aposentadoria. Quaisquer que sejam as limitações e os desafios que esses sistemas de arrecadação e de despesas enfrentam hoje, eles representam um imenso progresso histórico. (PIKETTY, 2014, p.13).

Habermas entende que o socialismo em seu nível cultural foi exitoso por difundir a educação, o que gerou maior criticidade na sociedade e dificulta a dominação. O que é uma barreira para o capitalismo desmedido, que não se adequaria como modelo econômico, sem provocar grandes crises. (HABERMAS, 2011, p. 58,59)

Nesse cenário, é necessária ponderação entre o resguardo dos direitos sociais e o desenvolvimento da economia. Assim, é essencial que se reflita como a intervenção estatal deve ser feita para garantir equilíbrio e eficiência. Em continuidade, o próximo tópico pretende discutir e aprofundar um pouco mais sobre o assunto.

\section{2-INTERVENÇÃO DO ESTADO FRENTE À ECONOMIA GLOBALIZADA}

Como foi tratado no tópico anterior, o Estado nacional como se apresenta atualmente tem passado por uma crise frente ao poder do capital privado, por esse motivo os mecanismos de ação e de intervenção no domínio econômico precisam ser repensados. Para compreender melhor o caminho a seguir, é essencial entender o processo que resultou na situação atual do Estado.

No texto "A constelação pós-nacional - Ensaios políticos" de Jürgen Habermas, especialmente em seu tópico "Duas fisiognomias do século", o autor fez uma retrospectiva histórica e retratou duas vertentes do pensamento provocadas pela história mundial. Importa salientar que fisiognomias é o estudo de marcas faciais causadas pelo tempo, como por exemplo, as rugas. O uso da expressão é uma analogia entre a face humana e a história, assim, 
o autor buscou entender a realidade atual baseando-se no estudo dos reflexos causados pelo tempo, por isso, em um primeiro momento o texto faz uma retrospectiva dos principais eventos do passado. (HABERMAS, 2011, p. 58,59)

Habermas, afirma que as guerras mundiais e o avanço da tecnologia, causaram na humanidade um reflexo profundo no modo de perceber e entender o mundo, em especial quanto ao tempo e ao espaço. O texto também trata de como a guerra fria polarizou as correntes de pensamento que ao final resultaram em um reconhecimento de que não é possível se falar em um modelo socialista extremo, mas que também fez com que o capitalismo fosse "domesticado" especialmente por conta de um avanço cultural, que permitiu uma abertura democrática da política. (HABERMAS, 2011, p. 58,59)

Sobre o mesmo tema, Hernando de Soto, em seu livro o "Mistério do Capital", afirma que após a queda do muro de Berlim, o modelo capitalista de economia prevaleceu, contudo, entende que é necessário um repensar do modelo levando em consideração a necessidade de garantir o direito dos pobres, e rever o capitalismo a partir da ótica dos mesmos. Na obra, o autor se questiona: por que o capitalismo prosperou em alguns países e em outros fracassou? Tal questionamento deve também ser alvo do questionamento do presente artigo, visto que, o modelo econômico é que vai guiar a forma de intervenção do Estado. (SOTO, 2001)

Importa lembrar que o capitalismo sem regras sequer foi o proposto por Adam Smith, que sabia que as leis de mercado eram imperfeitas, e dificilmente o Estado conseguiria intervir na economia com sucesso. No entanto, reconhecia a necessidade de existência do Estado, visto que, alguns serviços de interesse geral dificilmente seriam prestados voluntariamente, como: limpeza pública, segurança nacional. Em sua ótica o Estado também deveria garantir a honestidade dos bancos, proteger as patentes, estabelecer níveis educacionais e controlar as enfermidades. Ou seja, o referido autor reconhecia a necessidade de intervenção do Estado. (BURR, GOODWIN, 2012)

O grande problema da intervenção Estatal se dá quando essa intervenção visa beneficiar algum grupo específico de empresa ou setor, o que era visto com maus olhos por Adam Smith.

No contexto atual, um grande exemplo de falha na intervenção Estatal ocasionou a crise de 2008, que teve seu início nos Estados Unidos. Primeiramente houve a proliferação da criação de títulos derivados, que dificultavam a verificação de validade e o lastro dos mesmos, o Estado passou a não ter um controle eficiente sobre essas operações.

Confiando na idoneidade dos bancos, e acreditando que havia algum tipo de controle 
das agências do Estado sobre essas operações, muita gente investiu nas ações de crédito imobiliário. O problema é que, muitas delas não tinham valor real, e quando isso foi descoberto a crise se instaurou. No mesmo sentido José Eduardo Faria Lima:

Por seu caráter reducionista, a oposição entre Estado e mercado tende a obscurecer o enorme e complexo campo analítico que a crise financeira de 2008 e seus efeitos sobre a economia mundial oferecem aos cientistas sociais e aos juristas. A crise decorre tanto de fatores inéditos, como o crescimento descontrolado de derivativos, multiplicação de operações não padronizadas fora de mercados regulados, arbitragem com taxas de juros e taxas de câmbio, opacidade de muitos fundos de investimento, níveis elevados de alavancagem, conflitos de interesses de agências de classificação de risco, políticas de remuneração que incentivam os executivos financeiros a uma excessiva exposição de risco e coexistência de operações entre um conjunto de instituições regulamentadas e outras instituições em mercados sem nenhuma regulamentação, quanto de problemas já conhecidos nos registros de turbulências bancárias desde a Grande Depressão. (FARIA, 2009, p. 2)

O grande impasse pós-crise foi a forma como governo tratou o problema econômico, ao invés de socorrer a população que estava ficando desabrigada, o governo preferiu salvar os banqueiros. O documentário “Capitalism: A Love Story”, dirigido e escrito por Michael Moore, retratou bem a situação das famílias que perderam as casas devido à crise econômica de 2008 . Nesse ponto, os Estados Unido símbolo do liberalismo econômico acabou por realizar exatamente o que Adam Smith temia, a intervenção do Estado para beneficiar determinados grupos ou setores já privilegiados, e acabou demonstrando que os Estados Unidos não é um modelo perfeito de sucesso do capitalismo.

Os bancos enganaram o governo e a população, manipularam resultados e por fim sobreviveram ao caos criado. A população por sua vez, não teve a mesma atenção do Estado, o que sem dúvida, foi agravado pelo fato de nos Estados Unidos haver um reduzido número de investimento nos direitos sociais, em setores importantes como por exemplo, saúde e educação.

A crise ressoou em muitos países, contudo é possível dizer que os países que possuíam uma estrutura social criada, estavam mais bem preparados para enfrentar a recessão, o que minimizou os efeitos danosos, quando comparados aos efeitos da crise de 1929.

Pode-se afirmar que, o que aconteceu em 2008, foi o tipo de Intervenção estatal temida por Adam Smith, nesse caso o Estado interviu beneficiando os bancos. O problema é que esse tipo de manipulação do poder do Estado também está ocorrendo em nível internacional, como 
foi dito na primeira parte do presente trabalho. Em contrapartida, os autores tendem a acreditar que uma nova ordem dos países, baseada na união de forças para formar um Estado forte capaz de controlar o capital.

Não se pode desconsiderar tal posição, contudo é importante pensar que essa união traria uma homogeneização cultural e legislativa, que poderia inclusive facilitar a dominação do capital frente ao Estado. Nesse sentido, não seria mais necessário manipular a legislação de vários Estados, mas de apenas um, ou de poucos, caso os países sigam a tendência de se unir por blocos. Ademais, concentrar o poder pode não ser a opção mais tendente à democracia, visto que, utilizando das "fisiognomias" do mundo, citadas por Habermas, expressões de concentração de poder tendem a regimes totalitários.

Uma alternativa para tal situação é recuperar a credibilidade do Estado por meio da demonstração de eficiência. Bresser Pereira aponta como solução para aumentar a eficiência na administração pública, uma gestão focada nos resultados, por meio de uma reforma gerencial, o controle passa a ser exercido de forma diferente da tradicional administração burocrática, e passa a ser mais focado nos resultados e menos nos procedimentos. (PEREIRA, 2009).

Além da reforma na administração, uma reforma na legislação também poderia beneficiar a economia. Segundo Hernando de Soto, uma das explicações para o capitalismo não dar certo nos países pobres é pela ausência de uma infraestrutura jurídica, que possibilite um fluxo de capital de forma adequada. $\mathrm{O}$ autor realizou pesquisas que demonstram que há muito capital nos países pobres, mas a grande diferença é que nesses países esse capital não é regularizado, especialmente porque o processo de regularização é moroso e burocrático, demorando anos para se efetivar. Um exemplo dessa situação é o processo de legalização da propriedade nas Filipinas, onde o procedimento exige aproximadamente 168 fases e demora de 13 a 25 anos. Outro exemplo que pode ser citado é a legalização de uma propriedade no Peru, que possui cinco etapas, sendo que só a primeira delas tem 207 fases (SOTO, 2001).

Soto explica que o capital tem duas características que aqui podem ser traduzidas em "dar frutos" e "se multiplicar". O capital irregular pode ser caracterizado como uma cabeça de gado infértil, que consegue fornecer o leite, por exemplo, mas não consegue se replicar. Da mesma forma, uma moradia irregular serve de abrigo, mas, por ser irregular, não permite que seja dada em garantia para financiar um projeto do dono, o que possibilitaria a multiplicação do capital. A essa característica, Hernando de Soto atribuiu o nome de natureza extracorpórea do bem.

Outro exemplo que pode ser citado é o que trata das empresas. As empresas regulares 
permitem que seu capital seja aberto, gerando a escala ${ }^{5}$, mas a empresa irregular tem suas possibilidades de crescimento restritas pela sua condição de irregularidade. Assim, consegue no máximo, se expandir localmente, ou seja, até o raio em que inspira confiança. A característica de regular, chancelada pelo Estado, inspira segurança e permite que a mesma tenha maior credibilidade, atraindo investidores, gerando potencial econômico.

Talvez o que falte aos países menos desenvolvidos seja uma intervenção normativa do Estado, que vise facilitar o fluxo do capital, permitindo que a economia se desenvolva, ou seja, o Estado tem que criar mecanismos que facilitem o processo de regularização das atividades econômicas, para que a economia nesses países atinja escala mais facilmente.

Para tanto, é essencial que o procedimento para a regularização seja facilitado. Nesse sentido, Norberto Bobbio propõe as normas de incentivo, que visam facilitar o cumprimento das leis. O autor estudou técnicas de controle social, verificando que muitas vezes normas que optam por um caminho facilitador, como as que proporcionam sanções premiais, têm mais sucesso. Assim, é importante destacar que a diminuição da burocracia pode ser uma primeira facilitação proporcionada pelo Estado, para incentivar a regularização. (BOBBIO, 2007)

Hernando de Soto fez os cálculos de quanto de capital morto (pouco circulante) existe em alguns países subdesenvolvidos, e encontrou os seguintes dados:

Consideramos então o Peru, um país hispano-indígena-americano com tradição e constituição ética bem diferente. O valor dos imóveis rurais e urbanos extralegais no Peru monta a uns U\$76 bilhões. Isso representa cinco vezes o valor total da Bolsa de Lima antes da queda de 1998, 11 vezes o valor das empresas e instalações governamentais com potencial de privatização, e 14 vezes o valor de todo investimento estrangeiro direto no país por toda história documentada. (SOTO, 2001, p.46)

Outro país estudado pelo autor que demonstrou números expressivos foi o Egito, que possui a maior parte de sua população vivendo em moradias irregulares:

O valor do capital morto em forma de imóveis no Egito é, de acordo com a contagem feita com o auxílio de nossos colegas egípcios, de uns U\$240 bilhões. Isso representa 30 vezes o valor de todas as ações da bolsa do Cairo e, como já

\footnotetext{
${ }^{5}$ Gerar escala significa potencializar o crescimento e otimizar o uso dos recursos disponíveis. Pode-se dizer que quando uma empresa consegue abrir seu capital, ela aumenta a quantidade de recursos financeiro disponível, isso facilita sua expansão. Ocorre que, apenas as empresas regulares gozam de credibilidade para atrair investidores e crescer em escala.
} 
mencionei 55 vezes o valor de todo investimento estrangeiro no Egito. (SOTO, 2001, p. 47)

Importa comentar que quando o autor usa a expressão "capital morto", se refere ao capital não regularizado, que não consegue circular gerando mais riqueza.

Por fim, Soto conclui que "O valor total de imóveis de posse extralegal dos pobres no Terceiro Mundo e nas nações do extinto bloco comunista é de pelo menos US\$ 9,3 trilhões”. (SOTO, 2001, p. 47)

$\mathrm{Na}$ época em que foi escrito o livro, esse valor representava aproximadamente o dobro da moeda americana em circulação. "E o valor total de todas as empresas listadas nas principais bolsas de valores dos vinte países mais desenvolvidos do mundo: as bolsas de Nova York, Tóquio, Londres, Frankfurt, Toronto, Paris, Milão, o pregão Nasdaq e outras dezenas”. SOTO, 2001, p.49)

Como se pode perceber, há muito capital nos países subdesenvolvidos. Mas a falta de organização, gestão e regularização desse capital, dá a impressão de que o mesmo não existe. Importa lembrar que essas funções citadas são geralmente funções bem coordenadas em países considerados desenvolvidos. Assim, o presente artigo, propõe que se pense a intervenção estatal a partir dessa mudança de paradigma, em relação à figura e à função do Estado.

\section{CONCLUSÃO}

Assim, pode-se concluir que diante da vulnerabilidade da soberania econômica, é essencial que o Estado passe por uma reforma na sua administração e na sua forma de intervenção, a fim de restaurar seu equilíbrio. Para tanto, é essencial que o mesmo reestabeleça ao menos parte de sua soberania economicamente.

Nesse sentido, uma das opções viáveis é uma intervenção normativa do Estado, por meio de normas facilitadoras, se utilizando do proposto por Norberto Bobbio, favorecendo a diminuição da burocracia no que toca a regularização da economia. Tais medidas visam fornecer a infraestrutura jurídica para o crescimento da economia, permitido que haja um fortalecimento do capital público.

Especialmente porque, uma vez regularizado, o capital passa a fazer parte da teia de transações controladas pelo Estado, o que permite maior arrecadação de impostos e facilita a 
distribuição de renda e permite ao Estado ter forças para atuar adequadamente com o Capital privado representado pelas empresas. Para os particulares, a regularização é essencial para que se permita exigir do Estado uma postura de eficiência e inclusão em políticas de desenvolvimento.

Essa eficiência pode ser garantida com uma reforma na administração, desburocratizando procedimentos. Fazendo que que a atuação fiscalizadora do Estado seja mais aos resultados e menos aos procedimentos, fortalecendo a credibilidade do povo em relação ao Estado.

Por fim, grandes são os desafios do Estado frente a um aprofundamento da globalização e o crescimento do poder econômico do capital privado. Por esse motivo, é essencial que soluções não convencionais sejam consideradas para lidar com tal poder. $\mathrm{O}$ Estado como se conhece hoje pode ter que passar por adaptações, mas é possível que a ideia de soberania nacional econômica, prevaleça se houver uma reforma das estruturas hoje soberanas. A ideia de Hernando de Soto, que busca compreender o capital dos pobres com um olhar novo, pode contribuir para que o Estado se recupere e tenha forças para atuar frente ao capital privado. Como foi abordado, há muito capital desregulamentado que poderia agregar poder ao Estado. A proposta é que o Estado agregue esse capital por meio de uma intervenção normativa que facilite a integração desse valor nas relações controladas pelo Estado.

Com mais força, o Estado teria condições de manter suas obrigações sociais e continuar sendo uma barreira aos interesses do grupo de empresas de natureza privada. O que seria uma possível alternativa a corrente que entende que a junção dos países seria a única alternativa do Estado para fazer frente ao interesse do capital privado.

Por fim, o parente artigo demonstrou alguns aspectos das novas relações contemporâneas, dentre eles como os Estados têm se comportado frente o aumento do poder das empresas privadas, e como isso tem fragilizado as proteções legislativas impostas pelos países. Apresenta como um possível caminho para sobrevivência do Estado, uma reforma no seu modelo de atuação e uma intervenção normativa, que desburocratize e facilite a regulamentação do capital irregular para que o mesmo integre as relações controladas pelo Estado.

\section{REFERÊNCIAS}

ASSOCIAÇÃO BRASILEIRA DE NORMAS TÉCNICAS. NBR 10520. Rio de Janeiro, 
2002.

ASSOCIAÇÃO BRASILEIRA DE NORMAS TÉCNICAS. NBR 6023: Informação $e$ documentação: Referência. Rio de Janeiro, 2002.

ASSOCIAÇÃO BRASILEIRA DE NORMAS TÉCNICAS. NBR 6024. Rio de Janeiro, 2012.

ASSOCIAÇÃO BRASILEIRA DE NORMAS TÉCNICAS. NBR 6028: Informação e documentação Referências. Rio de Janeiro, 2003.

BANNWART JÚNIOR, Clodomiro José. Globalização, empresa e responsabilidade social. Scientia Iuridica - Tomo LXI, 2012. n. ${ }^{\circ} 330$

BOBBIO, Norberto. Da estrutura à função: novos estudos de teoria do direito. Manole: 2007.

BRASIL. Constituição (1988). Constituição da República Federativa do Brasil. Brasília: $1988 . \quad$ Disponivel em: http://www.planalto.gov.br/ccivil_03/Constituicao/Constituicao.htm. Acesso em: 02 mar. 2019.

BURR, Dan E, GOODWIN, Michael. Economix. Editora Abrams, 2012.

CASTELLS, Manuel. A era da informação: economia, sociedade e cultura. Fundação Calouste Gulbenkian. Serviço de Educação e Bolsas, 2011.

CENCI, Elve Miguel. Direito e globalização: o posicionamento de Habermas diante da proposta de uma constituição para a União Européia. Habermas em discussão: Anais do Colóquio Habermas realizado na UFSC. Florianópolis: NEFIPO, p. 63-68, 2005.

CRUZ, Paulo Márcio; BODNAR, Zenildo. Cosmopolitismo e Governança Transnacional Ambiental: Uma Agenda Para o Desenvolvimento Sustentável. Revista Direitos Humanos eDemocracia • Editora Unijuí • ano $4 \cdot$ n. 7 • jan./jun. • 2016 • ISSN 2317-5389. Programa de Pós-Graduação Stricto Sensu em Direito da Uniuí. Disponível em: https://www.revistas.unijui.edu.br/index.php/direitoshumanosedemocracia. Acesso em: 3 abr. 2019.

DINIZ, Eli; LIMA, Olaso Brasil de. Modernização autoritária: o empresariado e a intervenção do Estado na economia. 1986.

FORBS, Ranking 2018 das maiores empresas do mundo tem menos brasileiras. Disponível em https://forbes.uol.com.br/listas/2018/06/edicao-2018-da-global-2000-reune-19empresas- brasileiras/. Acesso em: 20 fev. 2019.

GIL, Antonio Carlos. Métodos e técnicas de pesquisa social. 6. ed. Editora Atlas SA, 2008.

HABERMAS, Jürgen. A constelação pós-nacional: ensaios políticos. Tradução de Márcio Seligmann-Silva. São Paulo: Littera Mundi, 2001 
IPRI, Instituto de Pesquisa de Relações Internacionais. As 15 maiores economias do mundo. Disponível em: Internacionaishttp://www.funag.gov.br/ipri/index.php/oipri/47- estatisticas/94-as-15-maiores-economias-do-mundo-em-pib-e-pib-p. Acesso em 22 fev.2019.

LIRA, Ricardo Pereira. Direito urbanístico, estatuto da cidade e regularização fundiária. Revista de Direito da Cidade, v. 1, n. 1, p. 261-276, 2007.

MARCONI, Marina de A.; LAKATOS, Eva M. Fundamentos de metodologia científica $2^{a}$ Ed. Editora Atlas, São Paulo, Brasil, 2007.

MARQUES NETO, Floriano Peixoto de Azevedo. Regulação Estatal e Interesses Públicos. São Paulo: Malheiros, 2002.

MARTINS, Luiz Gustavo Campana. Seminário Empresa e Direitos Humanos. Apresentação oral em 09/04/2019. Londrina, 2019.

MOORE, Michael. Capitalism: A Love Story. Documentário que retrata a situação das famílias que perderam as casas devido à crise econômica de 2008.

PEREIRA, Luiz Carlos Bresser. Construindo o Estado Republicano: democracia e reforma da gestão pública. Tradução: Maria Cristina Godoy. Rio de Janeiro: Editora FGV, 2009.

PIKETTY, Thomas. O capital no século XXI. Editora Intrínseca, 2014.

PRODANOV, Cleber Cristiano; DE FREITAS, Ernani Cesar. Metodologia do trabalho científico: métodos e técnicas da pesquisa e do trabalho acadêmico-2 ${ }^{a}$ Edição. Editora Feevale, 2013.GIL, A. C. Como elaborar projeto de pesquisa. 4. ed. São Paulo: Atlas, 2002

RICARDO, David. Princípios de economia política e tributação. LeBooks Editora, 2018.

SCHAPIRO, Mario Gomes. Novos parâmetros para a intervenção do Estado na economia. São Paulo: Saraiva, 2010.

SILVA, Edna Lúcia da; MENEZES, Estera Muszkat. Metodologia da pesquisa e elaboração de dissertação. 2001.

SINGER, Paul. Economia solidária. Iberoamerican Journal of Strategic Management (IJSM), v. 2, n. 1, p. 03-06, 2007.

SOTO, Hernando de. O mistério do capital: Por que o capitalismo dá certo nos países desenvolvidos e fracassa no resto do mundo. Rio de janeiro: Record, 2001. 